\title{
Formation of a Novel Polypyrrole/Porous \\ Phosphate Glass Ceramic Nanocomposite
}

\author{
Iara F. Gimenez, and Oswaldo L. Alves \\ Laboratório de Química do Estado Sólido, Instituto de Química, UNICAMP, \\ C.P. 6154, 13083-970 Campinas - SP, Brazil
}

\begin{abstract}
Este trabalho focaliza a obtenção de um novo nanocompósito, formado mediante a polimerização in situ de monômeros de pirrol na superfície dos poros de vitrocerâmicas porosas com esqueleto $\mathrm{LiTi}_{2}\left(\mathrm{PO}_{4}\right)_{3}$, após troca-iônica com cobre.
\end{abstract}

This work is concerned with evidences of a new composite system, formed by in situ polimerization of pyrrole moieties in the copper-exchanged pore surface of $\mathrm{LiTi}_{2}\left(\mathrm{PO}_{4}\right)_{3}$ glass ceramic.

Keywords: polypyrrole, porous glass-ceramics, nanocomposites

\section{Introduction}

Many aspects can justify efforts towards the preparation of conducting polymers within bulk matrices. When the host material has nanometric pores, occurence of crosslinking during the polimerization can be minimized by simple physical constraints, and as a consequence the electrical conductivity can be increased or decreased depending on the type of used matrix ${ }^{1}$. For instance, preparation of linear polypyrrole chains inside the pore structure of Porous Vycor Glass has been described by Alves and co-workers ${ }^{2-4}$. Alternatively, interest can arise when the porous host exhibits ionic conductive properties, such as the well known Nasicon-type solids ${ }^{5}$. In this context, this work reports the preparation of polypyrrole inside the pores of Nasicon-type $\mathrm{LiTi}_{2}\left(\mathrm{PO}_{4}\right)_{3}$ glass-ceramics 6 .

\section{Experimental}

Original glass samples of nominal composition $6 \mathrm{Li}_{2} \mathrm{O} .24 \mathrm{TiO}_{2} .39 \mathrm{CaO} .31 \mathrm{P}_{2} \mathrm{O}_{5}$ were prepared by melting reagent grade $\mathrm{Li}_{2} \mathrm{CO}_{3}, \mathrm{CaCO}_{3}, \mathrm{TiO}_{2}$ (anatase) and $\mathrm{P}_{2} \mathrm{O}_{5}$ in platinum crucibles at $1350{ }^{\circ} \mathrm{C}$ for $1 \mathrm{~h}$ in air. The melts were poured onto carbon plates and annealed at $630{ }^{\circ} \mathrm{C}$ for $1 \mathrm{~h}$. Glass-ceramic samples were prepared by the thermal treatment of the glasses at $630{ }^{\circ} \mathrm{C}$ for $24 \mathrm{~h}$ and subsequently at $720{ }^{\circ} \mathrm{C}$ for $12 \mathrm{~h}$. Immersion of glass-ceramic plates in 1 $\mathrm{Mol} / \mathrm{L} \mathrm{HCl}$ aqueous solutions, at room temperature for 24 $\mathrm{h}$, allows the formation of a continuous porous network. Exchange of $\mathrm{Li}^{+}$and $\mathrm{H}^{+}$ions originally present in the pore surfaces by $\mathrm{Cu}^{2+}$ ions was performed by immersion of the glass-ceramic plates in $1 \mathrm{Mol} / \mathrm{L} \mathrm{Cu}\left(\mathrm{CH}_{3} \mathrm{COO}\right)_{2}$ aqueous solutions, at room temperature for $24 \mathrm{~h}$.

Composite preparation was performed by heating the glass-ceramic samples in the excess of freshly distilled pyrrole, at the boiling temperature of the liquid during $1 \mathrm{~h}$. Raman spectra were recorded using a Renishaw Raman Imaging Microscope System 3000, using the $632.8 \mathrm{~nm}$ line of a He-Ne laser. Electron Scanning Micrographs were recorded using a MEV JEOL JSM T-300 Microscope.

\section{Results and Discussion}

According to TGA measurements, the amount of polymer present in the nanocomposite samples was found to be around $3.5 \%$ in weight. Figure 1 shows the photomicrographs of the glass-ceramic samples in (A) and of the nanocomposite samples in (B). The glass-ceramics exhibits fine-grained microstructures, with numerous voids present along the surface. After the growth of polypyrrole, a rough texture covering the ceramic surface can be observed.

The Fig. 2 shows Raman spectra obtained from different points on the surface of the same sample. A typical spectra of the original glass-ceramic can be observed in (D), showing only orthophosphate bands related to the $\mathrm{LiTi}_{2}\left(\mathrm{PO}_{4}\right)_{3}$ phase ${ }^{5}$, centered at 1003,986 and $966 \mathrm{~cm}^{-1}$. The spectra shown in $(\mathrm{B})$ and $(\mathrm{C})$ both reveal the coexistence of typical polypyrrole and phosphate bands. The spectrum shown in (A), however, is dominated by polypyrrole bands. Concerning the conductive polymeric phase, more than provide evidences of polymerization, the vibrational spectroscopies can be used to get information about 

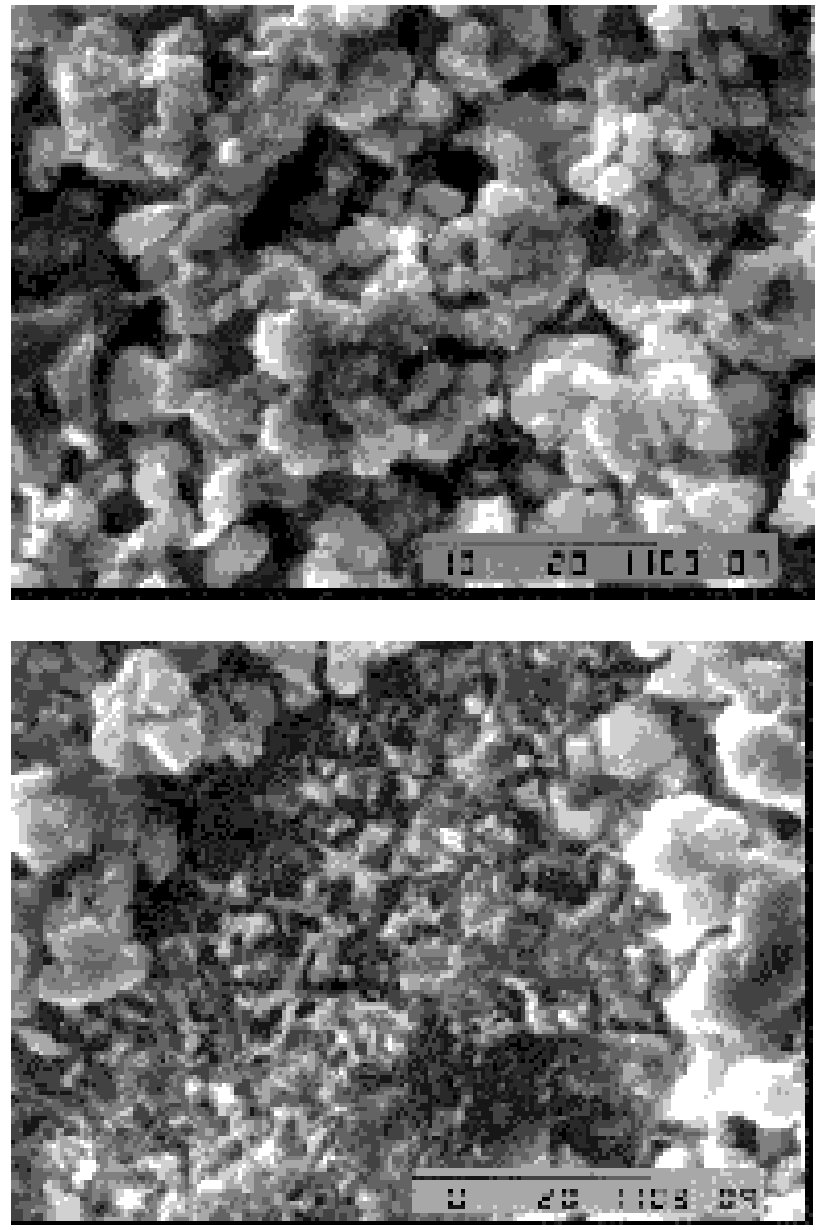

Figure 1. Scanning electron photomicrographs of: (A): an original porous glass-ceramic sample; (B): surface of a nanocomposite sample.

the degree of oxidation of conducting polymers ${ }^{7}$. In (A), the bands at $1594 \mathrm{~cm}^{-1}$ and $1360 \mathrm{~cm}^{-1}$ can be associated to the presence of polypyrrole in partially dopped states. In the neutral form of polypyrrole, the last band is most likely to occur above $1610 \mathrm{~cm}^{-1}$. Additionally, the bands observed near $943 \mathrm{~cm}^{-1}$ and $1048 \mathrm{~cm}^{-1}$ can be assigned to the structures responsible for charge transport through the chains, namely bipolarons and polarons ${ }^{7}$. Finally, the Raman spectra in Fig. 2 are in good agreement with those reported by Alves and co-workers ${ }^{2-4}$, for polypyrrole present in the pores of Porous Vycor Glass.

In summary, preliminary data reported here allows us to conclude that the porous copper (II) exchanged $\mathrm{LiTi}_{2}\left(\mathrm{PO}_{4}\right)_{3}$ glass-ceramics is a suitable host for obtaining stable nanocomposites through its interaction with polypir-

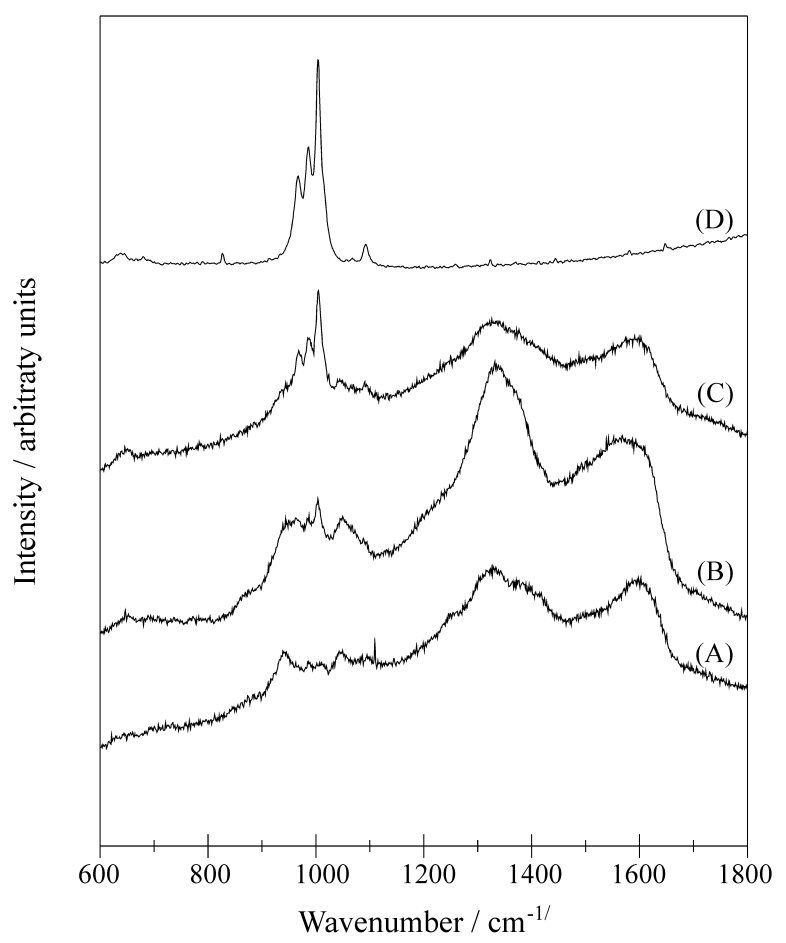

Figure 2. Raman spectra of: (A), (B) and (C): different points on the surface of a nanocomposite sample; (D): original porous glass-ceramic sample.

rol. Studies related with the electrical conductivity and redox properties are in progress in our laboratory.

\section{Acknowledgments}

The authors are gratefull to CNPq, Fapesp and PRONEX-MCT for the financial support.

\section{References}

1. Ruiz-Hitzky, E.; Aranda, P. An. Quim. Int. Ed. 1997, 93, 197.

2. Maia, D.J.; Zarbin, A.J.G.; Alves, O.L.; De Paoli, M-A. Adv. Mater. 1995, 7, 792.

3.Zarbin, A.J.G.; De Paoli, M-A.; Alves, O.L. Synth. Met. 1997, 84, 107.

4.Zarbin, A.J.G.; De Paoli, M-A.; Alves, O.L. Synth. Met. 1999, 99, 227.

5. Tarte, P.; Rulmont, A.; Merckaert-Ansay, C. Spectrochim. Acta 1986, 42A, 1009.

6. Hosono, H.; Zhang, Z.; Abe,Y. J. Am Ceram. Soc. 1989, 72, 1587.

7. Furukawa, Y.; Tazawa, S.; Fujii, Y.; Harada, I. Synth. Met. 1988, 24, 329.

Received: December 11, 1998

FAPESP helped in meeting the publication costs of this article 